\title{
POLÍTICAS PÚBLICAS DE EDUCAÇÃO NEOLIBERAL: UM BREVE BALANÇO
}

\section{PUBLIC EDUCATION POLICIES IN THE NEOLIBERAL CONTEXT: A BRIEF ASSESSMENT}

Erivania Melo de Morais ${ }^{1}$

UERN/Campus Assu: https://orcid.org/0000-0003-1839-6069

Camila Rodrigues dos Santos ${ }^{2}$

NEI-CAp/UFRN: https://orcid.org/0000-0001-5160-8081

Irene Alves de Paiva ${ }^{3}$

UFRN: https://orcid.org/0000-0002-2955-4328

DOI: 10.21680/1982-1662.2021v4n31ID25900

\section{Resumo}

Este artigo busca refletir acerca das políticas educacionais em contexto neoliberal que demarcou o cenário político brasileiro desde os anos 1990 e tem sido acentuado a partir de 2016 após o impeachment da Presidenta Dilma Rousseff, o que fomentou uma agenda de cortes e asfixiamento nas políticas sociais e na educação. Assim, elencamos como objetivos: contextualizar as políticas educacionais em seu processo de renovação e conservação da lógica neoliberal; e apontar as mudanças neoconservadoras em relação à política educacional a partir do governo Temer e Bolsonaro. Esta é uma pesquisa de caráter bibliográfico e documental em que

$1 \mathrm{E}$-mail: moraiserivania@gmail.com

2 E-mail: camila@nei.ufrn.br

$3 \mathrm{E}$-mail: irenealvesp@gmail.com 
buscamos problematizar criticamente as políticas educacionais. Nesse sentido, evidencia-se que ao longo desses 30 anos o ajustamento das políticas educacionais as condicionalidades dos organismos internacionais vêm se consolidando e apesar do processo de renovação política, manteve-se o afinamento com as concepções das agências multilaterais, que a partir dessa ascensão recente das perspectivas conservadoras através do processo de conservação dos ideais hegemônicos elitistas, que as políticas educacionais têm passado por um árduo decurso de ataques, seja em suas estruturas ou na produção e reprodução de representações, ideias, narrativas de eficácia, eficiência, produtivismo da educação numa perspectiva de resultados, afastando-se dos processos de conscientização e formação humanizada.

Palavras chave: Políticas educacionais. Reforma educacional. Neoliberalismo. Conservadorismo.

\begin{abstract}
This article seeks to reflect on the educational policies in a neoliberal context which has demarcated the Brazilian political scene since the 1990s and it has been accentuated since 2016 after the impeachment of the President Dilma Rousseff, which fostered an agenda of cuts and asphyxiation in the social policies and education. Thus, we listed as objectives: to contextualize the educational policies in their process of renewal and conservation of the neoliberal logic; and to point out the neoconservative changes in relation to the educational policy from the governments of the former President Michel Temer and the current President Jair Bolsonaro. This is a bibliographic and documentary research in which we seek to critically problematize educational policies. In this sense, it is evident that over these 30 years the adjustment of the educational policies to the conditionalities of the international organizations have been consolidating and despite the process of the political renewal, the tuning with the conceptions of the multilateral agencies has been maintained, which from this recent rise of the conservative perspectives through the process of the conservation of the elitist hegemonic ideals, that the educational policies have been through an arduous process of attacks, either in their structures or in the production and reproduction of representations, ideas, narratives of
\end{abstract}


effectiveness, efficiency, productivism of the education in a perspective of results, moving away from the processes of awareness and humanized formation.

Keywords: Educational policies. Educational reform. Neoliberalism. Conservatism.

\section{Introdução}

A década de 1990 inicia-se com a tentativa de superar a crise da dívida externa e dos acordos realizados com o Fundo Monetário Internacional (FMI), estas heranças da ditadura militar através de um processo de reestruturação econômica e com reformas do Estado tendo como base a política neoliberal que seria contraditoriamente a resposta a todos os problemas sociais do Brasil, dentre eles o da educação.

Apesar dessa tentativa ter sido realizada por Fernando Collor de Melo e Itamar Franco, foi apenas com Fernando Henrique Cardoso, que esse modelo neoliberal se intensificou e passou a demarcar as políticas nacionais de educação. E desde então, este modelo tem se perpetuado e reproduzido premissas que nos distanciam de uma educação equânime, democrática, capaz de promover a conscientização dos sujeitos e que nos leve a um processo de educação verdadeiramente coletiva, popular, inclusiva e libertária.

Nesse sentido, este artigo busca refletir acerca das políticas educacionais em contexto neoliberal que tem demarcado o cenário político brasileiro desde os anos 1990 e tem se acentuado no começo de 2016 após o impeachment da Presidenta Dilma Rousseff e que a partir da eleição de Jair Bolsonaro, tem promovido uma agenda de cortes e asfixiamento nas políticas de educação. Elencamos, desse modo, como objetivos: contextualizar as políticas educacionais em seu processo de renovação e conservação da lógica neoliberal; e apontar as mudanças neoconservadoras em relação à política educacional a partir dos governos de Temer e Bolsonaro.

A reflexão apresentada tem como base, uma pesquisa de caráter bibliográfico à luz de discussões críticas da educação brasileira em Saviani (2007) Libâneo, Oliveira e Toschi (2012), Coutinho (2013), Shiroma, Moraes e Evangelista (2002), Leher (2021) entre outros e documental, a partir de Leis, Decretos, Emendas Constitucionais, que nos permitiram problematizar criticamente as políticas educacionais. 
Para uma melhor compreensão, dividimos a reflexão em duas partes, a saber: “As políticas educacionais na interface das contradições restauração/renovação", onde problematizamos o início das políticas educacionais na interface do modelo neoliberal, analisando seus desdobramentos de conservação da lógica dominante de mercado e dos processos de renovação quando ao mesmo tempo em que há uma continuidade na garantia dos investimentos para os setores privados, há avanços populares; No outro ponto debatemos “As políticas públicas educacionais em contexto de restauração e conservadorismo", em que contextualizamos as políticas educacionais a partir do governo Temer e Bolsonaro, caracterizando o processo de agudização e do esfacelamento das políticas educacionais.

Nesse sentido, evidencia-se que ao longo desses 30 anos o ajustamento das políticas educacionais e as condicionalidades dos organismos internacionais vêm se consolidando, mesmo diante de um processo de renovação política, se manteve o afinamento com as concepções das agências multilaterais. E, a datar essa ascensão, nos últimos 5 (cinco) anos das perspectivas conservadoras, no processo de conservação dos ideais hegemônicos, que as políticas educacionais tem passado por um árduo decurso de ataques, seja em suas estruturas ou na produção e reprodução de representações, ideias, narrativas de eficácia, eficiência, produtivismo da educação numa perspectiva de resultados, afastando-se dos processos de conscientização das pessoas e de uma formação humanizada.

\section{As políticas educacionais na interface das contradições restauração/renovação}

Os anos de 1990 inaugurou no Brasil uma nova condução política e social com bases nas perspectivas neoliberais. Esse contexto trazia um dualismo reflexivo, se de um lado, estávamos iniciando um reencontro com a democracia, tendo como um dos marcos a elaboração da Constituição Federal de 1988, pós-ditadura militar, por outro lado, tínhamos muitos desafios, deixados por esse período marcado pelo desenvolvimentismo, mas, sobretudo, pelo agravamento das questões sociais da população brasileira.

Shiroma, Moraes e Evangelista (2002) contextualizam essa imersão do Brasil na interface da política neoliberal, apontando que essa influência advém das experiências com Thatcher na Inglaterra e com Reagan nos Estados Unidos, 
respectivamente. Esses dois modelos propuseram mudanças nas esferas sociais, políticas e ideológicas como forma de superação da crise que teve início com a reestruturação produtiva ${ }^{4}$ do capital datado em 1973 que provocaram mudanças profundas tanto no sistema capitalista como no sistema global do capital, cuja solução para esse momento seria via neoliberalismo que ganhou um terreno fértil apontando como principal causador dessa situação o Estado e as reivindicações sociais.

Essas transformações de cunho neoliberal no Brasil tiveram como ponto de partida a eleição de Fernando Collor de Mello para a Presidência da República, em que buscou sintonizar a exaltação do mercado e da hegemonia conservadora, rebatendo na educação como forma de reprodução social desse pensamento conservador, entretanto, o governo de Collor não se mantém, uma vez que "a aura populista e moralizante" que simbolizou o perseguidor dos “marajás" 5 , é interrompida com o seu impedimento em 1992.

A continuidade desse ideário neoliberal teve seguimento no governo de Itamar Franco, mas foi somente no governo de Fernando Henrique Cardoso que as reformas ganharam tangibilidade. Nesse contexto, a educação passou por diversas transformações, seguindo as orientações, sobretudo dos organismos multilaterais, do empresariado e de intelectuais que se colocaram como defensores das reformas, levando a produção e reprodução de um imaginário em que estavam "todos pela educação". Nesse sentido,

A reforma educacional brasileira em curso teve início com um elenco amplo de ações, porém sem aumento de recursos financeiros para manutenção e desenvolvimento do ensino. A centralização dos recursos em nível federal, no Fundo de manutenção e Desenvolvimento do Ensino Fundamental e da Valorização do Magistério (Fundef), possibilitou melhoria relativa nas áreas mais pobres do país, no entanto, provocou a perda do padrão educacional em centros maiores. (LIBÂNEO; OLIVEIRA; TOSCHI, 2012, p. 186).

Assim, no primeiro mandato de Fernando Henrique Cardoso (PSDB), foi apresentado o programa "Acorda Brasil: Está na hora da escola”, nas quais haviam algumas questões a serem alcançadas como por exemplo, distribuiçõos de verbas para

\footnotetext{
${ }^{4}$ Ricardo Antunes (2011) na introdução do Livro "A crise estrutural do capital” de Istvan Meszaros nos apresenta esse processo de reestruturação como uma forma sociometabolica do capital.

${ }^{5}$ Marajás - Termo utilizado por Collor para se referir aos servidores públicos de altos salários, servidores fantasmas e outros privilegiados que enriqueciam com o dinheiro público.
} 
as escolas, o avanço da qualidade do livro didático, a formação de docente via educação a distância, reforma nos currículos, através da organização dos Parâmetros Curriculares Nacionais (PCNs) e Diretrizes Curriculares Nacionais (DCNs), e ainda versava acerca da avaliação escolar. Todos esses pontos de reforma seguiam os mesmos direcionamentos internacionais orientados pelos organismos multilaterais que tensionam os avanços para a educação ou para qualquer política social.

Gadotti (1992) em suas reflexões acerca da educação e das políticas educacionais condensadas em ensaios oriundos de sua participação na Conferência Mundial "Educação para todos" em Jomtiem na Tailândia em 1990, nos apontava que as políticas educacionais enquanto políticas sociais se definem num campo de lutas hegemônicas e que, portanto, as estratégias, assim como, a elaboração de planos, programas não são definidos de forma neutra, mas traduzem interesses. E ainda suscita que o fracasso das políticas sociais são decorrentes da dívida externa, ressaltando que,

A influência da dívida sobre a educação é notória: diminuição de investimentos para cobrir pagamentos de juros é o principal da dívida; deterioração do padrão de ensino; piora do nível de vida geral da população reduzindo a sua capacidade de adquirir material escolar, manter-se informado, alimentar-se adequadamente e também reduzindo o tempo dedicado a atividades culturais e educativas, em função da necessidade de trabalhar mais cedo. (GADOTTI, 1992, p. 57. grifos nossos).

A dívida tem se colocado como uma das principais dificuldades de avanços nas políticas educacionais, uma vez que impede o fluxo de investimentos públicos para a educação. O Banco Mundial como gerenciador e protetor dos interesses dos grandes credores internacionais passou nesse período dos anos 1990 a "assegurar o pagamento da dívida externa e por empreender a reestruturação e abertura dessas economias, adequando-as aos novos requisitos do capital globalizado" (SOARES, 2009, p. 21).

Um exemplo dessa asfixia das políticas educacionais, no governo de Fernando Henrique Cardoso segundo Libâneo, Oliveira e Toschi (2012) poderia ser percebida com sua tentativa de constituir um projeto para reformar a educação brasileira, apresentado pelo seu Plano Nacional de Educação como continuidade do Plano Decenal de 1993, oriundo das sinalizações propostas pela Organização das Nações Unidas para a Educação, a Ciência e a Cultura (Unesco), pelo Fundo das Nações Unidas para a Infância (Unicef), pelo Programa das Nações Unidas para o Desenvolvimento 
(PNUD) e pelo Banco Mundial, ou seja, direcionado pelos organismos internacionais que passaram a liberar investimentos a partir de condicionalidades.

Esse Plano Nacional de Educação (PNE), ainda de acordo com Libâneo, Oliveira e Toschi (2012) foi elaborado pelo Ministério da Educação (MEC) e constituído de forma hierárquica, sem colaboração dos Estados, Distrito Federal e Municípios, mas foi construído a partir do Instituto Nacional de Estudos e Pesquisas Educacionais Anísio Teixeira (INEP) e de alguns interlocutores do Conselho Nacional de Educação (CNE), Conselho Nacional de Secretários de Educação (Consed) e União Nacional dos Dirigentes Municipais de Educação (Undime), sendo este o documento do MEC, entretanto, foi formulado outro projeto de bases mais populares, tendo como autor da primeira proposta o deputado Ivan Valente (PSOL-SP), realçando o tensionamento entre os diversos setores da sociedade civil, que resultou na aprovação do PNE 2001 2010 que propunha um aumento de 7\% da aplicação do PIB para a Educação, que foi vetado pelo então presidente Fernando Henrique Cardoso.

Após um período de dois mandatos em que a conservação dos ideais hegemônicos da direita conservadora, marcados pelas condicionalidades impostas pelo Banco Mundial e pela orientação neoliberal, estabelecido, sobretudo por redução dos gastos públicos, pela abertura comercial, pelas privatizações, entre outras medidas, provocaram tensionamentos sociais, uma vez que, todo esse conjunto de medidas foram sentidos de forma mais intensa nas classes populares e trabalhadoras.

Assim, o contexto social e a conjuntura política foram favoráveis para o processo de renovação com as eleições do presidente Luiz Inácio Lula da Silva (PT), que com uma agenda progressista passou a intentar os interesses hegemônicos conservador por meio de deliberações e ajustes, que mantinham o equilíbrio político, mas sem, propor transformações substantivas e estruturais.

Coutinho (2012) ao problematizar a contra reforma, aproxima-se do conceito de revolução passiva ${ }^{6}$, em que este, seria constituído por dois elementos importantes, que são: a restauração, ou seja, uma reação conservadora a possibilidade de uma transformação societária oriunda das classes populares e o outro elemento é o da renovação, que se trata do fato, de que algumas demandas populares, são atendidas "por alto", a partir do consentimento das classes dominantes, mas, sem, contudo, promover uma transformação social radical.

\footnotetext{
${ }^{6}$ Esse termo tem a sua reflexão no pensamento de Gramsci (1999), nos cadernos do cárcere, volume I.
} 
Nesse ínterim, apesar de reconhecer que os governos de cunho progressista, não conseguiram proporcionar essas transformações radicais e estruturais, foi possível observar como se aproximaram das pautas populares, em que promoveram reformas que permitiram avanços sociais, para a educação e para as políticas públicas educacionais.

Então, durante os governos de Luiz Inácio, que corresponderam respectivamente entre os anos de 2003 a 2006 e de 2007 a 2010, tivemos inúmeros avanços no que tange às políticas educacionais. O pernambucano Luiz Inácio, conhecido popularmente como Lula, tem origem popular e teve como proposta educacional "Uma Escola do Tamanho do Brasil”, que colocava a educação como prioridade e como ação para a transformação socioeconômica da sociedade brasileira. (LIBÂNEO; OLIVEIRA; TOSCHI, 2012).

Pela primeira vez, tínhamos um representante brasileiro, oriundo da classe trabalhadora, que sinalizava um caminho de mudanças e avanços no que diz respeito às políticas sociais para as camadas populares. Assim nos primeiros anos de mandato o Presidente Lula buscou implementar reformas na educação propostas em seu programa de governo que tinha como centralidade pensar a educação como o caminho e a ação para a transformação social.

Libâneo, Oliveira e Toschi (2012) salientam que o projeto de educação do Lula obedecia a três diretrizes gerais, a saber: a primeira destacada, seria a democratização do acesso e garantia de permanência, ou seja, a democratização não significava apenas construir escolas ou reformar, mas garantir as condições necessárias para o seu funcionamento e para a permanência dos estudantes; a segunda diretriz seria a qualidade social da educação, que considerava a qualidade como proposta de ampliação e diversificação das modalidades de ensino, permitindo que todos tivessem uma educação equânime; e a terceira, versava acerca da instauração do regime de colaboração e da democratização da gestão, que para efetivar o dispositivo da Lei de Diretrizes e Bases da Educação, Lei n 9394/1996, em vigor, a respeito da colaboração entre as esferas administrativas, encaminhou-se uma proposta de Lei para regulamentar a cooperação entre essas esferas, buscando uma maior articulação e também a reversão do processo de municipalização, demarcando um novo caminho de reciprocidade entre os entes federativos.

Nesse sentido, dentro dessa nova reforma na política educacional, 
estabelecendo uma pequena renovação, observou-se que algumas das metas propostas nesses primeiros anos foram alcançadas como, por exemplo, a criação do Fundo de Manutenção e Desenvolvimento da Educação (FUNDEB) por meio de uma Emenda Constitucional $n^{\circ} 53 / 2006$ e regulamentado pela Lei $n^{\circ} 11.494 / 2007$ e pelo Decreto $n^{\circ}$ 6.256/2007, no lugar do Fundef criado no governo de FHC, teve ainda a definição do custo-qualidade por aluno, entre outras metas que estavam em processos de tramitação como o Sistema Nacional articulado de educação, proposto para o novo Plano Nacional de Educação (PNE) e o Fórum Nacional de Educação instituído pela portaria $\mathrm{n}^{\circ} 1.407 / 2010$.

Uma outra política pública educacional de extrema importância de acordo com Silva (2019), foi o Programa de Reestruturação e Expansão das Universidade Federais (REUNI) iniciada no primeiro mandato e mantida no segundo que tinha o intento de ampliar o processo de expansão e interiorização das Universidades, ampliando o número de vagas, com a criação de novos cursos e com o crescimento das redes universitárias.

Durante o governo Lula, tivemos muitos fomentos no que tange às políticas educacionais do setor público, Dourado (2013) aponta que com o início do financiamento das instituições de educação superior (Institutos Federais e Universidades), abertura de concursos para o magistério superior e para técnicos administrativos, tivemos a institucionalização da Universidade Aberta do Brasil (UAB) via decreto $\mathrm{n}^{\circ} 5.800 / 2006$, como parte desse processo de expansão e interiorização dos cursos de formação e programas voltados para a diversidade como, por exemplo, as ações afirmativas via decreto $n^{\circ} 4.228 / 2002$. Direcionou também esforços para políticas públicas focadas para o setor privado, como a viabilização do financiamento da Educação Superior por meio do Programa Universidade para Todos (Prouni) criado pela Lei 11.096/2005 que viabilizou bolsas de estudo integrais e parciais para estudantes.

Outro programa que foi ampliado no governo Lula foi o Aperfeiçoamento do Fundo de financiamento ao Estudante do Ensino Superior (Fies), criado em 1999 pelo FHC e reformulado em 2010, oportunizando o financiamento de estudantes para cursar o ensino superior em instituições privadas, que de acordo com Silva (2010) foram medidas importantes no sentido de democratizar o ensino superior. Aponta ainda como direcionamento para essa democratização o Sistema de Seleção Unificado (SISU) 
publicado pela Portaria Normativa n. 2, de janeiro de 2010, ampliando a possibilidade de entrada na Universidade, uma vez que, os estudantes podem pleitear vagas em qualquer Instituição de Ensino Superior (IES) no Brasil.

Entre os anos de 2007 a 2010 fase do segundo mandato do presidente Lula, tivemos como ponto relevante para a política educacional a elaboração do Plano de Desenvolvimento da Educação (PDE) que reunia iniciativas para a melhoria na qualidade da educação nacional, passando desde os investimentos que deveriam ser destinados a educação até propostas de mobilização na sociedade acerca da função social da educação. Entretanto, é importante localizar que as ações elaboradas não tinham clareza em seus mecanismos de execução e gerenciamento, assim, Saviani (2007) aponta algumas críticas ao PDE interpelando se esse documento era de fato um plano de educação ou um programa de metas e que reproduzia muito do Plano Nacional de Educação de 2001:

Pode-se notar que as 30 ações que compõem o Plano de
Desenvolvimento da Educação incidem sobre os aspectos previstos no
Plano Nacional de Educação já que, como se mostrou, 17 dessas ações
estão referidas à educação básica; cinco se referem à educação
superior; sete dizem respeito às modalidades de ensino; e uma ação
(estágio) se dirige simultaneamente ao ensino médio, educação
tecnológica e profissional, e educação superior. Observa-se que não há
ação dirigida especificamente à modalidade de ensino “educação
indígena”, nem ao financiamento e gestão. No entanto, o FUNDEB,
além de dizer respeito ao financiamento e gestão, contempla
explicitamente a educação indígena e quilombola. (SAVIANI, 2007, p.
1239).

Assim, Saviani (2007) aponta que o PDE aparece como um conjunto de ações que almeja constituir estratégias para implementar os objetivos e metas no Plano Nacional de Educação (PNE), e portanto não parte de uma avaliação diagnóstica dos objetivos, das diretrizes, mas se forma a partir de ações que não se articulam com este.

Nesse sentido, avaliou como assertiva a decisão do MEC de reunir a aceitação da opinião pública a respeito da qualidade do ensino, manifestada pelas mídias e por setores privatistas, citando o "Compromisso Todos pela Educação", como sendo um momento profícuo em que se buscava ampliar a importância da educação, entretanto, chama a atenção para a ponderação de credulidades em crer indiscutivelmente nos bons propósitos das elites econômicas e políticas, destacando que na ocasião em 2006 
a então presidente deste movimento era a maior acionista individual do Banco Itaú, campeã no voluntariado e que afirmava a união de todos os brasileiros, da cooperação, do esforço entre empresas e governos para a construção de escolas boas e de oportunidades iguais para todos, mas apesar de entendermos os avanços dessa unidade pró-educação, é preciso um exercício de reflexividade dentro das contradições do ideário empresarial e neoliberal, que encontra-se imerso sob uma “pedagogia dos resultados", seguindo "uma lógica de mercado que se guia, nas atuais circunstâncias, pelos mecanismos das chamadas "pedagogia das competências" e “qualidade total”. (SAVIANI, 2007, p. 1243)

Já as políticas educacionais no período da Presidenta Dilma Rousseff (PT), primeira mulher eleita Presidenta do Brasil, que se deu entre os anos de 2011 a 2016, tiveram uma agenda de certa continuidade do governo anterior, como efetivar algumas ações do Plano de Desenvolvimento da Educação, desde a criação de novos cursos universitários no interior como ampliação da oferta da educação básica, ampliação de creches e pré-escolas, com aumento de recursos para oferta de cursos técnicos e para a valorização da carreira docente.

De acordo com Silva (2019) durante o governo Dilma, a Secretaria de Educação Continuada, Alfabetização, Diversidade (secad) criada em 2004, foi ampliada para Secretaria de Educação Continuada, Alfabetização, Diversidade e Inclusão (Secadi) por meio do Decreto n. 7.480, de 16 de maio de 2011, ganhou o eixo de educação inclusiva, buscando a garantia da democratização e universalização do ensino. Outro ponto destacado foi a aprovação da Emenda Constitucional n. 59, de 11 de novembro de 2009, que modificou os artigos 208, 211, 212 e 214 da Constituição Federal brasileira, instituindo a obrigatoriedade e gratuidade da educação básica para estudantes entre quatro e dezessete anos de idade a partir de 2016, proporcionando a oferta gratuita para aqueles que não acessaram anteriormente.

Dilma Rousseff em 2011 estabeleceu a criação do Programa de Acesso ao Ensino Técnico e Emprego (Pronatec), através da Lei n.12.513, oportunizando melhores condições e expandindo a oferta de educação profissional e tecnológica para as instituições públicas e privadas através do sistema S. Propôs ainda a Lei 12.711/2012, que instituiu o sistema de cotas raciais para pessoas autodeclaradas negras, pardas, indígenas e pessoas com deficiência para ingresso nas instituições federais de educação ampliando o processo de democratização do ensino, entretanto, é 
importante apreender o conjunto do que isso significou, ou seja, apesar desse esforço e de todos os investimentos para as políticas públicas educacionais, observou-se nos governos Lula e Dilma de acordo com Silva (2019, p. 61) "um movimento de mercantilização do ensino superior e a submissão dos estudantes mais pobres a IES de pior qualidade, caso das privadas de modo geral”.

\section{As políticas públicas educacionais em contexto de restauração e conservadorismo}

Como vimos anteriormente, a datar os anos 90 que a ofensiva neoliberal vem se configurando em sua principal fase, articulando e mantendo as estruturas conservadoras, entretanto, observou-se um movimento de renovação nos governos ditos progressistas e pós-neoliberais ${ }^{7}$, que proporcionaram avanços nas políticas educacionais na relação com o processo de democratização do acesso e permanência a educação. Löwy (2016) reflete que o Estado democrático é excepcional, porque o que vêm predominando nos últimos dois séculos seria um Estado de exceção, afirmando que a democracia "... é um peso para o Estado, para as classes dominantes e para o capital financeiro" (LÖWY, 2016, p. 61).

Então, esses anos nos quais Lula e Dilma estiveram a frente da administração pública, não agradaram inteiramente as elites, as oligarquias, os banqueiros, os latifundiários, os industriais, que apesar de muitas concessões e acordos, não consentiram ao fato do governo incorporar na agenda alguns interesses dos setores populares, sem que deles precisassem para tomada de decisões, configurando uma certa perda de controle o que os deixou insatisfeitos com esse lugar.

Assim, em 2016 tivemos o resultado da insatisfação das elites e dessa disputa de poder tensionadas nos últimos anos, que destitui a Presidenta eleita democraticamente Dilma Rousseff, com um golpe de Estado, em que Parlamentares (senadores e deputados) disseram "sim", para as suas famílias, para a religião, para a corrupção, para o conservadorismo, para o consentimento de uma política que anularia as conquistas sociais e por tanto, nos poucos avanços que foram conquistados com as políticas educacionais.

O vice-presidente Michel Temer (MDB) assumiu a condução da política no Brasil

\footnotetext{
${ }^{7}$ Sader (2013) afirma que os governos de Lula e Dilma se caracterizaram como pós-neoliberais, por constituir elementos de ruptura com o modelo neoliberal de Collor, Itamar e FHC.
} 
e dentre as suas primeiras medidas que atravessavam não apenas a educação, mas outros setores sociais foi a Emenda constitucional n. 95 de 15 de Dezembro de 2016, que institui um novo regime fiscal em que congelou o orçamento para investimentos em educação, saúde, seguridade social por 20 anos, inviabilizando, portanto, qualquer possibilidade de avanço. Esse retorno à conservação dos ideais das elites brasileiras foram apresentados como "Uma ponte para o futuro" 8 , um documento que não escondia as suas intenções de preservar a economia e o mercado financeiro, com Temer esse caminho foi privilegiado e garantido.

As reformas educacionais dentro de uma perspectiva privatista foram a tônica da vez, desse governo, expressando de forma clara "um projeto de sociedade que prioriza os valores associados à sobrevivência do capitalismo internacional, em detrimento do investimento em melhoria da qualidade de vida da população..." (MELO; SOUSA, 2017, p. 31)

Assim, dentro dessas mudanças no que tange a educação, tivemos a Medida Provisória (MP) n. 746/2016, que posteriormente foi transformada na Lei 13. 415/2017 que instituiu a reforma do ensino médio, realizada com muita rapidez e de forma impositiva, seguindo os ditames neoliberais. Mas por que dessa urgência?

Um dos argumentos advindos do MEC seria em virtude de que, essa reforma proporcionaria o desenvolvimento para o crescimento econômico, sendo o caminho propulsor a educação profissional, investindo no capital humano para o aumento da produtividade e ampliação das condições de competitividade internacional. Nesse sentido, tendo como orientação para a formação dos estudantes a perspectiva do mercado, do capital,

Enfatiza os conhecimentos úteis que o estudante deve adquirir para impulsionar a produtividade dos setores econômicos, a fim de potencializar a competitividade nos mercados local e internacional, ou para criar condições de empregabilidade, isto é, desenvolver habilidades e competências que potencializem a inserção do indivíduo no mercado de trabalho. A formação humana é diretamente articulada com a formação da força de trabalho, sendo esta considerada um dos fatores de produção, assim como o maquinário. Trata-se de uma concepção predominante na história da educação brasileira, legitimada em políticas públicas de educação em diferentes momentos dos ciclos do capital. (MOTTA; FRIGOTTO, 2017, 358)

Ou seja, os argumentos constituídos para se alinhar a lógica de mercado, como

\footnotetext{
${ }^{8}$ Documento lançado no segundo semestre de 2015 pelo PMDB.
} 
por exemplo, o caminho para o "progresso", não são recentes. No período da ditadura militar, marcada pelo desenvolvimentismo, preconizava essa teoria do capital humano, como forma de modernizar o país, atualmente dentro dessa lógica globalizada, neoliberal, neoconservadora, essa justificativa se embasa na competitividade do mercado internacional e usa-se de diversas estratégias para produzir e reproduzir essas ideias, narrativas sobre a educação estar a serviço do mercado. Assim, a ofensiva neoliberal necessita ser vista para além do econômico, mas como uma perspectiva de luta entre as diversas visões de sociedade, uma vez que,

Neoliberalismo e o neoconservadorismo convergem então para moldar um cenário educacional em que as possibilidades de construir uma educação pública como um espaço público de discussão e exercício da democracia ficarão cada vez mais distantes. (SILVA, 2015, p. 26)

Ainda durante o governo Temer tivemos a conclusão do texto da Base Nacional Comum Curricular (BNCC), que delineava a partir da construção do currículo nacional essa orientação para o mercado, para a formação do capital humano, para uma formação em habilidades e competências, para o desenvolvimento do protagonismo juvenil, e para a relação da vida com formas diversas de empreender.

A BNCC seguindo as direções do Plano Nacional de Educação (PNE) 2014-2021, que estimulou como vimos o processo de privatização do ensino, buscou de acordo com Santos e Morais (2019, p. 16) "definir um conjunto de aprendizagens essenciais para orientar a educação em todo o país”. Essa organização curricular foi inicialmente constituída de forma democrática, a partir de uma construção coletiva em que professores puderam participar, entretanto, em 2016 com as mudanças na orientação política, essa formulação se alinhou estritamente as condicionalidades dos organismos internacionais e ratificou as perspectivas voltadas para uma formação pautada no capital humano, na formação para o desenvolvimento econômico.

Em 2019, as reformas de asfixiamento das políticas educacionais se intensificaram com a eleição de Jair Messias Bolsonaro (PSL), que não só manteve a conservação do ideário neoliberal e neoconservador, como aprofundou esse processo com uma política de desvalorização da educação, de sucateamento das universidades, de restrição de recursos para ciência e tecnologia, concentrando os seus esforços numa política para o mercado, para setor financeiro, para os ruralistas. 
Antes mesmo de se concretizar esse cenário do contexto atual brasileiro, havia no plano de governo do atual presidente, "O caminho da prosperidade" 9, que anunciava as alterações que implementaria, caso fosse eleito, dentre os quais estavam as mudanças no conteúdo e no ensino, preconizando disciplinas como português, matemática e ciências, sem “doutrinação e sexualização precoce”, "expurgando a ideologia de Paulo Freire", seria um dos caminhos para essas mudanças através Base Nacional Comum Curricular (BNCC), transformando os caminhos formativos que buscassem aumentar a produtividade, fomentando o empreendedorismo, para que os jovens com seus protagonismos conseguissem “abrir suas próprias empresas”.

E essas orientações nas quais foram defendidas, são uma continuidade do que estava acontecendo no governo Temer e aprofundada, ou seja, não eram premissas alheias da relação com os organismos internacionais, uma vez que, os relatórios do Banco Mundial no que tange a educação coloca nas suas proposições respectivamente nos anos de 2018, concretizar a promessa da educação. Assim, as perspectivas do Banco Mundial e o trabalho técnico na área da educação seguem uma abordagem integrada para criar, apoiar e reforçar sistemas educacionais que oferecem ensino às crianças, aos jovens e aos que estão em fases mais adiantadas da vida, voltadas para a qualificação, colocando pontos como fortalecer a filantropia e o setor privado, e para a colaboração do capital humano, em 2019 o relatório adensa essa orientação da qualificação para a produtividade das futuras gerações de trabalhadores e a máxima de "Investir em capital humano para o crescimento e a prosperidade", e o relatório de 2020 aponta mais uma vez a questão do investimento em capital humano.

Então é observado não só um alinhamento, mas um projeto societário das elites brasileira em curso, tomando um formato concreto através das políticas de governo, assim a reflexão realizada por Ribeiro (1986), que afirmava que a crise educacional do Brasil da qual tanto se fala, não seria uma crise, mas um programa em curso, cujos frutos, falarão por si mesmo. Esse programa em curso se traduz em muitas políticas que cerceiam qualquer possibilidade de democratização, de formação consciente, de equidade para a educação, voltando seu esforço para a produtividade e para as bases econômicas.

Durante o governo Bolsonaro, foram implementadas algumas políticas públicas educacionais, que demonstram essa contramão democrática. Uma dessas políticas

\footnotetext{
${ }^{9}$ Disponível no site do TSE - Tribunal Superior Eleitoral
} 
foram instituídas pelo Decreto 9.765/2019 que regulamentou a Política Nacional de Alfabetização, denominada Tempo de Aprender, no qual parte da premissa colaborativa entre pais, professores e gestores para combater o analfabetismo, sem contudo, apresentar investimentos, recursos, ou direcionamentos no que tange a sistematização dessa formação colaborativa, o programa não considera o desenvolvimento científico das pesquisas atuais sobre a alfabetização e aposta na proposta ultrapassada pautada na decodificação das palavras. 0 processo de alfabetização não é algo simples, mas detona uma compreensão ampla dos sistemas de aprendizagem.

Um outro projeto dentro da Política educacional do atual governo foi o Futurase publicado no site da Casa Civil no final de maio de 2020, através do Projeto de Lei PL n. 3076/2020 na câmara e protocolizado no dia 2 de junho de 2020, declarava seu embate com as Universidades, buscando combater o comunismo e estimular o desenvolvimento de uma Universidade empreendedora e inovadora. De acordo com Leher (2021) o Futura-se está inserido, no contexto da estratégia de "Guerra cultural" 10, como parte da ofensiva neoliberal e neoconservadora da extrema direita. Assim,

Evidentemente a estratégia neoliberal de conquista hegemônica não se limita ao campo educacional, embora ele ocupe aí um lugar privilegiado, como um dos muitos elementos passíveis de serem utilizados como técnica de governo, regulação e controle social. 0 que estamos presenciando é um processo amplo de redefinição global das esferas social, política e pessoal, no qual complexos e eficazes mecanismos de significação e representações são utilizados para criar e recriar um clima favorável à visão social e política liberal. 0 que está em jogo não é apenas uma reestruturação neoliberal das esferas econômica, social e política, mas uma reelaboração e redefinição das próprias formas de representação e significações sociais. 0 projeto neoconservador e neoliberal envolve, centralmente, a criação de um espaço em que se torne impossível pensar o econômico, o político e o social fora das categorias que justificam o arranjo social capitalista. (SILVA, 2015, p. 13)

O Futura-se enquanto orientação neoconservadora de uma política de educação está em um lugar de disputa, em que são criadas na esfera social, outros sentidos, significados e representações que estão para além da perspectiva econômica, mas que produz e reproduz uma lógica social em consonância com as narrativas dominantes de

\footnotetext{
${ }^{10}$ Ver em Guerra Cultural e Universidade Pública: O Futura-se é parte da estratégia de silenciamento do Roberto Leher.
} 
que é um programa que vai garantir a autonomia financeira das Universidades para que possam investir no empreendedorismo e em novidades voltadas para geração de emprego, entretanto, camufla as contradições desse processo, tendo em vista que o ajuste fiscal estabelecido pela Emenda Constitucional (EC) n.95 inviabiliza essa boa vontade de avançar a educação.

Além desse processo de silenciamento das Universidades, que demonstra uma sistemática bem arquitetada a partir das orientações do mercado e do combate ideológico, instituindo no início de janeiro de 2019 o Programa Nacional das Escolas Cívico-Militares (Pecim) via Decreto $n^{\circ} 10.004$ de 5/9/2019, estabelece como finalidade a melhoria da qualidade do ensino fundamental e médio, tendo como argumento combater a violência dentro dos ambientes escolares, que segundo Ricci (2019) são justificativas espetaculares, dramáticas e situacionais, uma vez que, não representa a totalidade dos sistemas escolares, mas que fomenta “ $O$ adestramento nas escolas e o discurso ideologizado passam a se alinhar com a pregação da coação e da coerção institucionalizada na educação” (RICCI, 2019, p. 109).

Desde que assumiu a Presidência, Bolsonaro tem se esforçado para garantir e colocar em prática, todo o seu projeto previamente anunciado durante a sua candidatura, a máxima do Estado mínimo tem sido exteriorizado e instituído de forma autocrática, sem diálogos de forma inflexível, assegurando as benesses ao mercado, ao sistema financeiro, ao capital.

0 ano de 2020, além da continuidade dessa agenda de desmonte das políticas sociais, do sucateamento das Universidades e Institutos Federais, por meio da redução do orçamento e os cortes de investimentos, da reelaboração das orientações dos sistemas de ensino da educação básica, de detratar os profissionais da educação que tiveram que lutar para garantir os recursos para valorização da educação via Fundo de Manutenção e Desenvolvimento da Educação (Fundeb) ${ }^{11}$. Fomos surpreendidos por uma Pandemia, que ao invés de ter sido tratada com seriedade e com análises em que pudessem diagnosticar a totalidade da situação, optou-se por negar, por inviabilizar recursos, incentivar uso de medicamentos ineficazes, tratando a pandemia e sua

\footnotetext{
${ }^{11}$ A lei n. 14.113 de 25 de Dezembro de 2020, regulamentou o novo Fundeb que tinha sido atualizado pelo então Ministro Fernando Haddad em 2007 e tinha como vigência o final de 2020. Em 2015 propuseram uma Proposta de Emenda Constitucional - PEC 15/15, para tornar o fundo permanente, proposta tensionada pela sociedade civil e pelo governo Bolsonaro, que seu Ministro da economia Paulo Guedes, articulou todos os esforços, para que os recursos subsidiassem e que não garantisse a permanência de investimentos para as escolas públicas e para a valorização dos profissionais da educação. A proposta do Guedes não foi votada e por unanimidade votou-se para o Fundeb permanente.
} 
gravidade como uma "gripezinha” (adjetivo usado pelo Presidente Bolsonaro para se referir a Pandemia) acentuando premeditadamente as desigualdades sociais que arremeteram consequentemente as classes populares e trabalhadoras.

Recentemente em abril de 2021 através do Decreto 10.686, bloqueou as dotações orçamentárias primárias discricionárias, que são os orçamentos para serviços públicos e um dos que foram mais afetados foi o da educação, que teve mais de 2,7 bilhões de recursos paralisados, como demonstrado abaixo,

Tabela 1: Bloqueio de orçamento para 2021.

\begin{tabular}{|l|l|l|}
\hline \multicolumn{2}{|l|}{ Orgãos/Unidades Orçamentárias } & Valor do Bloqueio \\
\hline 20000 & Presidência da República & 56.054 .305 \\
\hline 22000 & Ministério da Agricultura, Pecuária e Abastecimento. & 283.157 .304 \\
\hline 24000 & Ministério da Ciência, Tecnologia e Inovações. & 372.326 .930 \\
\hline 25000 & Ministério da Economia & 1.406 .425 .452 \\
\hline 26000 & Ministério da Educação & 2.728 .636 .813 \\
\hline
\end{tabular}

Fonte: (DOU, Decreto $\mathrm{n}^{\circ} \mathbf{1 0 . 6 8 6 / 2 1 )}$

Observa-se com esse decreto, que dentre os orçamentos bloqueados destacamse aqueles destinado à área da ciência, da pesquisa, dos investimentos públicos e da manutenção das estruturas públicas como as Universidades. Essas áreas têm sido desde o começo de 2019 anuladas e prejudicadas com essa política financeirista que utiliza os recursos que deveriam ser investidos em políticas de saúde, compra de vacinas, para o pagamento de auxílio emergencial digno à população, e para a educação, garantindo condições de trabalho aos docentes, viabilizando recursos para os estudantes, que não conseguem acompanhar as aulas remotas porque muitos não possuem internet ou instrumentos tecnológicos que o permitam seguir nesse formato.

Em plena pandemia o governo federal veta cerca de 1,1 bilhões e bloqueia orçamento para a educação, em 2,7 bilhões de reais, que poderiam ter sido investidos e garantidos o direito ao acesso e a permanência de muitos estudantes, entretanto em contraposição, temos esforços desse grupo político de bases neoliberais e neoconservadoras, com as narrativas de que são a favor da educação, e que é preciso voltar às suas atividades, mas não investe para que esse retorno seja de forma segura, como por exemplo, apoiar e agir para que os profissionais da educação possam ser vacinados como grupos prioritários. 
Mas, ao contrário de pensar em políticas públicas que assegurassem o avanço da educação, apesar de todos os desafios postos pela pandemia, precariza a possibilidade desse avanço e responsabiliza os docentes, encabeçando ideias de que nesse contexto os profissionais da educação não trabalham, tonificando as narrativas conservadoras, autoritárias, e deslocadas da realidade educacional brasileira.

\section{Considerações finais}

Durante os últimos 30 anos, presenciamos a sofisticação do projeto societário capitalista que através de sua ofensiva neoliberal que tem transformado a política educacional em síntese de orientações dos organismos multilaterais, de forma a emplacar uma série de condicionalidades para os países latino-americano com a justificativa de reformar o Estado e desenvolvê-lo do ponto de vista econômico, sendo a educação o provedor dessa ação através da formação para o capital humano e para a produtividade. Isso foi observado no governo de Fernando Henrique Cardoso que inaugurou essa direção milagrosa e contraditória de combater as desigualdades sociais, desenvolvendo quase que exclusivamente o sistema econômico, caracterizando o que Coutinho (2012) denominou de "restauração" da velha ordem política.

Entretanto, dentro dos tensionamentos políticos e sociais, tivemos em 2002 um processo de "renovação" dentro das perspectivas de Coutinho (2012) em que algumas demandas populares são atendidas com o consentimento dos grupos dominantes, iniciava-se os governos populares de Lula e posteriormente da Dilma, que apesar de muitos esforços para ampliar as políticas públicas e em específico de educação, percebeu-se segundo Silva (2019) uma intensificação de medidas educativas pautadas na eficiência e eficácia dos seus serviços, contrariando o sentido inclusivo políticas, contribuíram para a ascensão dos sistemas privados de ensino e para endossar as ideias de desenvolvimento de mercado, de produtividade, de competitividade, obscurecendo ideias de uma educação como prática para a liberdade, para a conscientização, para a democratização, para a justiça social.

Ideias que passaram a ser duramente criticadas a partir de 2016, quando a extrema direita com sua guerra cultural passa a disputar as narrativas, entoando o anticientificismo, o negacionismo, e o resgate da moralidade, a religiosidade dos bons 
costumes dos “cidadãos de bem", em que se substancializa em 2019, quando se concretiza no plano institucional e político a orientação mais austera da condução das políticas educacionais e sociais, que foi intensificado com a pandemia em 2020.

Nesse cenário temos dois desafios, um, reivindicar, lutar por políticas públicas que garantam o funcionamento da educação e dos setores públicos e o segundo a resistência contra o negacionismo, conservadorismo e a política neoliberal como uma expressão do capitalismo que se coloca ainda mais forte, que segundo Zizec (2020, P. 97) “aproveitando-se do desastre da pandemia para se alavancar; vamos todos acabar aceitando silenciosamente" e precisamos mais que nunca nos conscientizar da realidade e assim, buscar alternativas políticas, democráticas e sociais para vencer a insipiência, a incompreensão, a incredulidade, a imprudência, a insensatez que tem se perpetuado na cotidianidade e ao longo dos anos de forma a manter as estruturas estruturadas hegemonicamente a partir de opressões e retirada de direitos das classes populares brasileira.

\section{Referências}

BRASIL. Lei 13. 415 de 16 de Fevereiro de 2017. Institui a Política de Fomento à Implementação de Escolas de Ensino Médio em Tempo Integral. Disponível em: www.planalto.gov.br/ccivil_03/_ato2015-2018/2017/lei//13415.htm Acesso 10 de maio de 2021.

. Presidência da República. Emenda Constitucional n 95, de 15 de dezembro de 2016. Altera o Ato das Disposições Constitucionais Transitórias, para instituir o Novo Regime Fiscal, e dá outras providências. Diário Oficial da União, Brasília, DF, 15 dez. 2016. Disponível em: Emenda Constitucional $\mathrm{n}^{\circ} 95$ (planalto.gov.br). Acesso em 24 de maio de 2021.

- Decreto $\mathrm{n}^{\circ}$ 5.800, de 8 de junho de 2006. Dispõe sobre o Sistema Universidade Aberta do Brasil - UAB. Disponível em: Decreto n 5800 (planalto.gov.br). Acesso em 20 de maio de 2021.

Decreto $\mathrm{n}^{\circ}$ 9.765, de 11 de abril de 2019. Institui a Política Nacional de Alfabetização. Disponível em: D9765 (planalto.gov.br) Acesso em 20 de maio de 2021.

. Lei $\mathrm{n}^{\circ} 11.096$, de 13 de janeiro de 2005. Institui o Programa Universidade para Todos - PROUNI, regula a atuação de entidades beneficentes de assistência social no ensino superior; altera a Lei $\mathrm{n}^{\circ} 10.891$, de 9 de julho de 2004, e dá outras providências. Disponível em: Lei n 11.096 (planalto.gov.br) Acesso em 20 de maio de 2021.

- Lei $\mathrm{n}^{\circ} 12.513$, de 26 de outubro de 2011. Institui o Programa Nacional de Acesso ao Ensino Técnico e Emprego (Pronatec). Disponível em: $\underline{\text { L12513 }}$ (planalto.gov.br) Acesso em 20 de maio de 2021. 
- Lei $\mathrm{n}^{\circ} 12.711$, de 29 de agosto de 2012. Dispõe sobre o ingresso nas universidades federais e nas instituições federais de ensino técnico de nível médio e dá outras providências. Disponível em: L12711 (planalto.gov.br) Acesso em 20 de maio de 2021.

. Medida provisória $n^{\circ} 746$ de 2016. Diário Oficial [da] República Federativa do Brasil, Poder Executivo: Brasília, DF, 23 set. 2016. Edição Extra. Disponível em: mp_746_2016_ensino_medio_integral.pdf (mppr.mp.br) Acesso em 15 de maio.

- Ministério da Educação. Base Nacional Comum Curricular. Brasília: 2018. Disponível em: BNCC_El_EF_110518_versaofinal_site.pdf (mec.gov.br) Acesso em 15 de maio de 2021.

Plano Nacional de Educação (PNE) 2014-2024. Disponível em: PNE - Plano Nacional de Educação - Plano Nacional de Educação - Lei $n^{\circ}$ 13.005/2014 (mec.gov.br). Acesso em 10 de maio de 2021.

.decreto $n^{\circ} 4.228$, de 13 de maio de 2002. Institui, no âmbito da Administração Pública Federal, o Programa Nacional de Ações Afirmativas e dá outras providências. Disponível em: D4228 (planalto.gov.br). Acesso em 20 de maio de 2021.

MEC / CNE. Parâmetros Curriculares Nacionais para o Ensino Médio: Área Ciências Humanas e suas Tecnologias. Brasília, DF, 2000. Disponível em Acesso em: Microsoft Word - Ciências da Natureza.doc (mec.gov.br) 10 de Maio de 2021.

ANTUNES, Ricardo. A substância da crise. In: MÉSZÁROS, István. A crise estrutural do capital. 2 ed. São Paulo: Boitempo, 2011. p. 9-16.

COUTINHO, Carlos Nelson. A época neoliberal: revolução passiva ou contrarreforma? Novos Rumos, Marília, v. 49, n. 1, p. 117-126, jan./jun. 2012.

DAVIES, Nicholas. 0 financiamento público às instituições privadas de ensino. Revista Agenda Social. Rio de Janeiro, v. 10, n. 1, p. 134-146, 2016. Disponível em: o financiamento púlico às instituições privadas de ensino | davies | revista agenda social. Acesso em: 19 de Maio de 2021.

DERMEVAL, Saviani. O plano de desenvolvimento da educação: análise do projeto do MEC. Educ. Soc., Campinas, vol. 28, n. 100 - Especial, p. 1231-1255, out. 2007

DIÁRIO OFICIAL DA UNIÃO. Decreto $n^{\circ}$ 10.686, de 22 de Abril de 2021 que dispõe sobre o bloqueio de dotações orçamentárias primárias discricionárias e dá outras providências. Disponível em: decreto $\mathrm{n}^{\circ} 10.686$, de 22 de abril de 2021 - decreto $\mathrm{n}^{\circ}$ 10.686, de 22 de abril de 2021 - dou - imprensa nacional (in.gov.br) Acesso em 08 de maio de 2021.

DOURADO, L. F.. Políticas de educação superior: avanços e desafios. In: GENTILI, P. (Org.). Política educacional, cidadania e conquistas democráticas. São Paulo: Editora Fundação Perseu Abramo, 2013. 59-66p

FRIGOTTO, Gaudêncio. A Educação está nocauteada. Entrevista publicada por EPSJV/Fiocruz,15-06-2018. Disponível em http://www.epsjv.fiocruz.br/noticias/entrevista/a-educacao-esta-nocauteada. Acesso em: 19 de maio de 2021.

FUNDO NACIONAL DE DESENVOLVIMENTO DA EDUCAÇÃO (FNDE). Fundo de Manutenção e Desenvolvimento da Educação Básica (FUNDEB) Disponível em: Portal do FNDE Fundeb. Acesso em 15 de maio de 2021

GADOTTI, Moacir. Diversidade cultural e educação para todos. Rio de janeiro: Graal, 1992.

GRAMSCI, Antonio. Cadernos dos cárceres. Rio de Janeiro: Civilização Brasileira, 1999.

LEHER, Roberto. Universidade Pública Federal Brasileira: Future-se e "Guerra Cultural 
como expressões da autocracia burguesa. Educ. Soc., Campinas, v. 42, e241425, 2021. Disponível

em:

https://www.scielo.br/j/es/a/TSQSX7dwJVVGyYW8bVFmWYm/?format=pdf\&lang=pt

Acesso em 16 de maio de 2021.

LIBÂNEO, José Carlos; OLIVEIRA, João Ferreira de; TOSCHI, Mirza Seabra. Educação Escolar: políticas, estruturas e organização. São Paulo Cortez, 2012.

LÖWY, Michael. Da tragédia à farsa: o golpe de 2016 no Brasil. In: JINKINGS, Ivana; DORIA, Kim; CLETO, Murilo (Orgs). Por que gritamos golpe? Para entender o impeachment e a crise política no Brasil. São Paulo: Boitempo, 2016. p. 61-67.

MELO, Adriana Almeida Salles de; SOUSA, Flávio Bezerra de. A agenda do mercado e a educação no Governo Temer. Revista Germinal: marxismo e educação em debate, Salvador, Universidade Federal da Bahia, v. 9, n. 1, p. 25-36, 2017. Disponível em: Disponível

em:

https://rigs.ufba.br/index.php/revistagerminal/article/view/21619/14336 Acesso em: 20 de maio.

MOTTA, Vânia Cardoso da; FRIGOTTO, Gaudêncio. Por que a urgência da reforma do ensino médio? Medida provisória $n^{\circ}$ 746/2016 (lei $\left.n^{\circ} 13.415 / 2017\right)$. Educ. Soc., Campinas, v. 38, $\mathrm{n}^{\circ}$. 139, p.355-372, abr.-jun. Disponível em: https: / / www.scielo.br/j/es/a/8hBKtMRjC9mBJYjPwbNDktk/?lang=pt\&format=pdf.

Acesso em 10 de março de 2021.

PLANO DE GOVERNO DO JAIR BOLSONARO: CAMINHOS DA PROSPERIDADE. Disponível em: Propostas de governo dos candidatos ao cargo de Presidente da República Tribunal Superior Eleitoral (tse.jus.br). Acesso em 08 de maio de 2021.

PMDB. UMA PONTE PARA O FUTURO, 2015. Disponível em: uma-ponte-para-ofuturo.pdf (fundacaoulysses.org.br) Acesso em: 20 de março 2021.

$\mathrm{RICCl}$, Rudá. A militarização das escolas. In:_CÁSSIO, Fernando (Org). Educação contra a barbárie: por escolas democráticas e pela liberdade de ensinar. São Paulo: Boitempo, 2019. p. 107-114.

SADER, E.. A construção da hegemonia pós-neoliberal. In: SADER, E. (Org). 10 anos de governos pós-neoliberais no Brasil: Lula e Dilma. São Paulo, Boitempo; Rio de Janeiro: FLACSO Brasil, 2013. 135-145 p. Disponível em: 10_ANOS_GOVERNOS.pdf (unesp.br). Acesso em 15 de maio de 2021.

SANTOS, Camila Rodrigues; MORAIS, Erivania Melo. BNCC: Fundamentos epstemológicos para a formação docente. In: SANTOS, Camila Rodrigues; SBRUSSI, Márcia de Paula Brilhante Portela; NEVES, Vilma Lúcia da Silva (Orgs). BNCC em debate: Como fica a docência? Curitiba: CRV, 2019. p. 15-32.

SHIROMA, Eneida Oto; MORAES, Maria Célia Marcondes de; EVANGELISTA; Olinda.. Política Educacional. 2 ed Rio de Janeiro: DP\&A, 2012.

SILVA, Ana Maria Clementino Jesus. As tensões e contradições das políticas educacionais brasileiras dos governos de Lula e Dilma Rousseff: o Ideb e o Programa Mais Educação. Tese de doutorado, universidade de minas gerais faculdade de educação. Belo Horizonte 2019. 269p. Disponível em: https://repositorio.ufmg.br/handle/1843/31802 Acesso em 10 de maio de 2021.

SOARES. Banco Mundial: Políticas e reformas. In: TOMMASI, Livia de; WARDE, Mirian Jorge; HADDAD, Sérgio (Orgs). O Banco Mundial e as políticas educacionais. 6 ed. São Paulo: Cortez, 2009, p. 15-40.

ZIZEK, Slavoj. Pandemia: Covid - 19 e a reinvenção do comunismo. São Paulo: Boitempo, 2020. 
Recebido: 22 jun 2021 Aceito: 9 jul 2021 